\title{
Prospects for the use of spherical gold nanoparticles in immunization
}

\author{
Sergey A. Staroverov ${ }^{1} \cdot$ Alexei A. Volkov ${ }^{2} \cdot$ Pavel V. Mezhenny $^{2} \cdot$ Ivan Yu. Domnitsky ${ }^{2} \cdot$ Alexander S. Fomin $^{1}$. \\ Sergey V. Kozlov ${ }^{2} \cdot$ Lev A. Dykman ${ }^{1} \cdot$ Olga I. Guliy ${ }^{1,2}$
}

Received: 20 September 2018 / Revised: 17 October 2018 / Accepted: 19 October 2018 / Published online: 6 November 2018

(C) Springer-Verlag GmbH Germany, part of Springer Nature 2018

\begin{abstract}
Recent years have seen extremely fast development of new viral nanovaccines and diagnostic agents using nanostructures prepared by biological and chemical synthesis. We used spherical gold nanoparticles (average diameter, $15 \mathrm{~nm}$ ) as a platform for the antigen for swine transmissible gastroenteritis virus (TGEV). The literature data demonstrate that immunization of animals with the TGEV antigen coupled to gold nanoparticles (GNPs) not only activates antigenpresenting cells but also increases the proliferative activity of splenic lymphoid (antibody-forming) cells. The contents of $\gamma$-IFN, IL-1 $\beta$, and IL-6 in animals immunized with GNP-antigen conjugates were found to be higher than those in intact animals or in animals given the antigen alone. The increased concentration of IL-1 $\beta$ in the immunized animals directly correlated with the activity of macrophages and stimulated B cells, which produce this cytokine when activated. The increased concentration of IL- 6 indicates that the injected preparations are stimulatory to cellular immunity. Immunization with the TGEV antigen conjugated to GNPs as a carrier activates the respiratory activity of lymphoid cells and peritoneal macrophages, which is directly related to their transforming activity and to the activation of antibody generation. Furthermore, the use of this conjugate allows marked improvement of the structure of the animals' immune organs and restores the morphological-functional state of these organs. The microanatomical changes (increased number of follicles) indicate the activation of the B-dependent zone of the spleen and, consequently, the development of a humoral-type immunological reaction. The degradative processes observed in the animals immunized with TGEV antigen alone are evidence of weak resistance to pathogen attack. These results can be used to develop vaccines against this infection by employing TGEV antigen coupled to gold nanoparticles as a carrier.
\end{abstract}

Keywords Swine transmissible gastroenteritis · Virus antigen · Immunization · Guinea pig · Gold nanoparticle · Nanovaccine · Immune system organs

\section{Introduction}

Swine transmissible gastroenteritis is an acute, rapidly spreading, highly contagious enteric disease of pigs of all ages. It is characterized by vomiting, watery and yellow diarrhea, weight loss, and rapid dehydration, leading to a high mortality rate, especially in piglets (mortality decreases with age).

Olga I. Guliy

guliy_olga@mail.ru

1 Institute of Biochemistry and Physiology of Plants and Microorganisms, Russian Academy of Sciences, Saratov, Russian Federation

2 Saratov State Vavilov Agrarian University, Saratov, Russian Federation
Swine transmissible gastroenteritis is caused by transmissible gastroenteritis virus (TGEV) of the genus Coronavirus in the family Coronaviridae. The major route of virus transmission is fecal-oral. Infected animals cannot digest food properly and die from dehydration.

The disease causes great economic losses in pig farms all over the world, and the primary means of animal protection against it is vaccination (Cheng and Niu 1992; Straw et al. 2000). Therefore, the development of new vaccines and the implementation of large-scale vaccination programs are important in pig breeding (Moxley and Olson (1989).

In several countries, vaccination against swine transmissible gastroenteritis is conducted effectively but only with inactivated monovalent and combined vaccines not recognized internationally. Traditional inactivated vaccines have high contents of contaminant substances (up to 99\%), causing side effects, and/or may contain, as inactivating 
compounds, toxic agents such as phenol and formaldehyde, normally used to inactivate microbial cells. Moreover, traditional vaccines are usually low immunogenic, because killed microorganisms cannot induce fully functioning cellular immunity. Therefore, there is a need to develop new, more effective, and less costly vaccines against swine transmissible gastroenteritis (Mout et al. 2012).

Recent years have seen extremely fast development of new viral nanovaccines and diagnostic agents using nanostructures prepared by biological and chemical synthesis. In particular, this can be attributed to the development of biocompatible inorganic nanomaterials - gold nanoparticles. Gold nanoparticles are stable metallic nanoparticles which have excellent surface functional chemistry, high biocompatibility, and nil toxicity. In addition, gold nanoparticles can be easily synthesized, giving them shapes such as spheres, rods, cubes, stars, and pyramids. Several reports have described the development and use of nanostructures for the delivery of biologically active agents to target cells (Mout et al. 2012; Bhattacharya and Mukherjee 2008; Staroverov et al. 2012). To reach their target cells in vivo, nanoparticles must bypass many barriers that protect animals against antigens (Dreaden et al. 2012).

Gold nanoparticles (GNPs) have been used widely as carriers of antigens and therapeutic agents in human medicine, veterinary practice, and biology (Dykman and Khlebtsov 2012). Of particular interest is the ability of GNPs to induce humoral immune response to weakly immunogenic antigens and haptens (Dykman et al. 2010a; Dykman et al. 2010b). Moreover, GNPs conjugated to TGEV have an immunostimulatory effect (Dykman et al. 2010b).

We studied the immunological variable and morphological changes in the immune organs of guinea pigs immunized with TGEV antigen conjugated to GNPs as a nanocarrier.

\section{Materials and methods}

\section{Antigen}

TGEV strain VN-96 was taken from the Museum of Strains of the Laboratory of Virology (Scientific Research Veterinary Institute, Russian Academy of Sciences, Saratov) and deposited in the All-Russian State Collection of Microbial Strains Used in Veterinary and Animal Husbandry by the number "VN-96" (patent RU2009124039A 2009). TGEV strain VN-96 with a titer of 6.5-7.5 $\mathrm{lg} \mathrm{TCD}_{50} \mathrm{ml}^{-1}$ was used. Test cultures were inoculated with the same strain at $4.0 \mathrm{lg} \mathrm{TCD}_{50} \mathrm{ml}^{-1}$ after $72 \mathrm{~h}$ of cultivation. TGEV was purified in a sucrose gradient according to Horzinek et al. (1982). The resultant virus suspension was used for protein analysis by sodium dodecyl sulfate-polyacrylamide gel electrophoresis (SDS-PAGE) at a constant voltage of $80 \mathrm{~V}$ for $20 \mathrm{~min}$ and then at $200 \mathrm{~V}$ for $3 \mathrm{~h}$ (Maniatis et al. 1982). For molecular mass determinations, Precision Plus Protein ${ }^{\mathrm{TM}}$ Kaleidoscope ${ }^{\mathrm{TM}}$ prestained protein standards no. 1610375 were used. The results of protein separation were processed with the Gel-Imager and Gel Explorer, version 1.0, programs (DNA-technology, Moscow). Genome identity was checked by polymerase chain reaction (PCR) using a specific primera conservative part of TGEV's $S$ genome, containing 886 base pairs (bp) (Herrington and McGee 1993). RNA was isolated from TGEV by using a NucleoS+TM suspension silicate sorbent (Biokom, Moscow) according to the manufacturer's instructions. PCR results were recorded on a transilluminator with a DNA-analyzer video system.

PCR products obtained from a preparation of the TGEV strain VN-96 were analyzed by electrophoresis in agarose gel (1.5\%) using DNA Ladder 100 as a molecular size marker and DNA of bacteriophage $\lambda$ as a negative control.

As viral nucleic acid is responsible for virulence, it was inactivated, after being isolated from TGEV and purified, with ribonuclease (RNAase), a hydrolase enzyme that catalyzes RNA hydrolysis. The inactivation was done by the procedure described by Fedorova et al. (2011). The antigen resulting from nucleic acid inactivation was used for animal immunization.

\section{Conjugation of viral antigen to GNPs}

Spherical gold nanospheres (average diameter, $15 \mathrm{~nm}$ ) were made by the citrate method of Frens (1973). For reduction, $242.5 \mathrm{ml}$ of $0.001 \%$ aqueous tetrachloroauric acid (HAuCl4; Sigma-Aldrich) was heated under reflux to $100^{\circ} \mathrm{C}$ on a magnetic stirrer in an Erlenmeyer flask. This was followed by the addition of $7.75 \mathrm{ml}$ of $1 \%$ aqueous sodium citrate to the flask.

The particle diameter was found as described earlier (Khlebtsov and Dykman 2010), by using a Libra 120 transmission electron microscope (Carl Zeiss, Germany), a Specord S 250 spectrophotometer (Analytik Jena, Germany), and a Zetasizer Nano-ZS particle size and zeta potential analyzer (Malvern).

To prepare antigen-gold nanoparticle conjugates, we found the "gold number" (minimal amount of antigen that protects the sol against salt aggregation) for the antigen solution. To this end, $20 \mu \mathrm{l}$ of an antigen solution in PBS (initial concentration, $1 \mathrm{mg} \mathrm{ml}^{-1}$ ) was titrated twofold on a 96-well microtiter plate. Each well received $200 \mu \mathrm{l}$ of GNPs and $20 \mu \mathrm{l}$ of $1.7 \mathrm{M}$ $\mathrm{NaCl}$. The minimal stabilizing concentration for the antigen was $12.5 \mu \mathrm{g} \mathrm{ml}^{-1}$. Conjugation was done by simple mixing (without the use of coupling agents) (Dykman et al. 2008).

\section{Animals}

Thirty six male guinea pigs, weighing $300-350 \mathrm{~g}$ at the time the experiment started, were used. The animals were cared for and handled in compliance with the Guide for the Care and Use of Laboratory Animals, the European Convention 
for the Protection of Vertebrate Animals Used for Experimental and Other Scientific Purposes, and the legislation of the Russian Federation.

\section{Immunization procedure}

For immunobiological studies, the guinea pigs were divided into four groups of nine each. The animals were immunized subcutaneously along the spinal column by two injections with an interval of 10 days between. The guinea pigs in group 1 were injected with $1.0 \mathrm{ml}$ of TGEV antigen-GNPs (antigen concentration, $12.5 \mu \mathrm{g}$ per animal). Group 2 received $1 \mathrm{ml}$ of TGEV antigen solution (12.5 $\mu \mathrm{g}$ per animal). Group 3 served as the control, which received $1 \mathrm{ml}$ of physiological saline. Group 4 served as the control GNPs, which received $1 \mathrm{ml}$ of GNPs solution. GNP-antigen group was in comparison with group which received only physiological saline (control group). The animals were killed 10 days after the last injection, and blood serum samples were taken for immunological studies. Immediately after removal, all pieces of tissues and organs were placed in a fixing solution (10\% aqueous neutral formalin), and then $15-\mu \mathrm{m}$-thick histological sections were prepared on a freezing microtome, model 2515 (Reichert Wien, Austria). All histological samples were stained with hematoxylin-eosin.

\section{Isolation of peritoneal macrophages and splenic lymphocytes}

For isolating peritoneal macrophages, the animals were killed and then fixed on their backs. An incision was made along the midline of the anterior abdominal wall, and the skin flap was carefully separated, with care taken to keep the peritoneum intact. After a puncture had been made with a needle connected to a syringe, $50 \mathrm{ml}$ of PBS, $\mathrm{pH} 7.2$, was injected into the peritoneal cavity. The anterior abdominal wall was then gently massaged, and after 5-7 min, peritoneal fluid was collected with a Pasteur pipet through a cut made in the peritoneum and was filtered into a test tube through a nylon filter. The cells were washed three times by centrifugation in PBS at $750 \mathrm{~g}$, after which they were resuspended in $1 \mathrm{ml}$ of PBS and counted in a Goryaev chamber. Peritoneal macrophages were cultured by standard procedures (Leiter 2001).

For isolating splenic lymphocytes, an incision was made along the white line of the peritoneum after peritoneal macrophages had been isolated, and the spleen was removed. The spleen was minced with scissors, and the tissue pieces were mashed through a fine sieve into a petri plate containing sterile PBS. The resulting suspension was subjected to ficoll-urografin density-gradient centrifugation. The lymphocyte ring was collected in a new test tube. The lymphocytes were washed three times by centrifugation in PBS, $\mathrm{pH}$ 7.4 , at $750 \mathrm{~g}$ for $10 \mathrm{~min}$, and the cell sediment was resuspended in $1 \mathrm{ml}$ of PBS. The lymphocytic cells were counted with a HaemaScreenvet hematology analyzer (Hospitex Diagnostics, Italy).

\section{Analysis of immunological variables and of changes in spleen morphology}

The titer of antibodies in the sera was estimated by enzyme-linked immunosorbent assay (ELISA) with horseradish peroxidase-labeled antibodies against guinea pig IgG (Jackson ImmunoResearch, UK). The synthetic peptide was used as the immobilized antigen. The reaction results were recorded on a Plate Screen microplate spectrophotometer. The interleukin concentration in the sera was measured with a Plate Screen analyzer (Hospitex Diagnostics, Italy) and using reagents of IL- $1 \beta$, IL-6, and INF- $\gamma$ (Vector-Best, Russia).

Respiratory activity was measured conventionally (Bernas and Dobrucki 2000) by the ability of cells to reduce nitrotetrazolium blue [3-(4,5-dimethylthiazol-2-yl)-2,5diphenyl tetrazolium bromide, MTT (Sigma-Aldrich)] to formazan. Briefly, suspensions of known concentrations of isolated animal cells (macrophages and lymphocytes) were centrifuged at $1000 \mathrm{~g}$ for $10 \mathrm{~min}$, and the sediment was resuspended in $1 \mathrm{ml}$ of $0.05 \%$ MTT and incubated at $37^{\circ} \mathrm{C}$ for $1 \mathrm{~h}$. After incubation, the cells were centrifuged at $4000 \mathrm{~g}$ for $10 \mathrm{~min}$ and the sediment was resuspended in $0.5 \mathrm{ml}$ of dimethyl sulfoxide (Fluka, Switzerland). The amount of reduced formazan was measured with a Genesys 10S UV-vis spectrophotometer at $490 \mathrm{~nm}$. To construct the calibration curve, we used commercial formazan (Sigma-Aldrich) at 0.002, 0.02, 0.2 , and $2 \mathrm{mg} \mathrm{ml}^{-1}$.

For studying possible morphological changes in the spleen as an important part of the macrophage system, the animals were immunized with TGEV antigen-GNPs. The control group comprised of nonimmunized animals. We used the spleens of guinea pigs of the same physiological age. Longitudinal and transverse spleen sections (15- $\mu \mathrm{m}$-thick) were prepared on a freezing microtome, model 2515 (Reichert Wien, Austria), by following standard procedures. Histological sections were differentially stained with hematoxylin-eosin.

\section{Statistics}

The results were statistically processed by the standard procedures using Student's $t$ test to evaluate the reliability of the differences between samplings in the experimental and control studies. After the arithmetic mean and the standard deviation for a given data sample were found, we determined the standard error of the arithmetic mean and its confidence limits by Student's $t$ coefficient $(n, p)$ at a significance level of $95 \%(p=0.05)$. 
The obtained results were statistically processed by the standard procedures integrated in Excel 2007 software (Microsoft Corp., USA). After the arithmetic mean and the standard deviation for a given data sample had been found, we determined the standard error of the arithmetic mean and its confidence limits with account of Student's $t$ coefficient ( $n$, p) [number of measurements $n=9$, significance level $=95 \%$ $(p=0.05)]$. These results are presented as histograms. The significance of differences between individual samples was evaluated by a two-sample unpaired Student's $t$ test with unequal variances. Differences were considered significant when the experimentally found $p_{\exp }$ value was $\leq 0.05$.

The reliability of the changes recorded in the results of each of the experiments described above for the entire set of antigen formulations examined was assessed by one-way analysis of variance (ANOVA) by using Fisher's ratio test. The dependences found were considered significant at $F>F_{\text {crit, }}$, where the critical value $F_{\text {crit }}$ at $n=9$ and $m=4-5$ (number of data sets) corresponded to $p=0.05$ (with the number of degrees of freedom ( $d f)$ lying between 4 and 14) and the effective value $p_{\text {eff }}$ was $<0.05$.

\section{Results}

Swine transmissible gastroenteritis is caused by an RNA virus belonging to group 1a of the genus Alphacoronavirus in the family Coronaviridae. The virion has a spherical shape with a diameter of 75-160 nm (Martins et al. 2013). The viral nucleocapsid is a flexible spiral containing single-stranded RNA and a large number of nucleocapsid protein molecules (Delmas et al. 1986; Sturman et al. 1985). The virus replicates in the cytoplasm of mature epithelial cells located at the ends of the intestine villi. A general scheme of the experiment is depicted in Fig. 1.

After the antigen was isolated and its protein composition was analyzed by SDS-PAGE, we found that the molecular masses of the separated proteins were identical to those of the TGEV proteins. The antigen contained the following proteins: $\mathrm{P}$ protein (large surface glycoprotein S; molecular mass, 170-200 kDa), N protein (basic nucleocapsid protein, 50 $62 \mathrm{kDa}$ ), and $\mathrm{M}$ protein (matrix membrane protein, 25$35 \mathrm{kDa}$ ) (Fig. 2). A protein fraction of 15-17 kDa was also present. According to Wesley et al. (1991), $17 \mathrm{kDa}$ is the size of an unglycated structural protein of TGEV. Thus, all known TGEV proteins were separated.

The TGEV nucleic acid was identified by PCR using a specific primer - a conservative part of TGEV's $S$ genome, containing $886 \mathrm{bp}$. Analysis of the PCR products from a purified preparation of the TGEV strain VN-96, which was done by agarose gel electrophoresis with DNA Ladder 100, demonstrated sufficiently high separation of cDNA (Fig. 3). The presence of only a characteristic cDNA fraction (size, $886 \mathrm{bp}$ ) indicated the presence of the TGEV genome in the sample.

After the virus's nucleic acid was inactivated with ribonuclease, the resultant antigen (a mixture of viral capsid proteins) was used for conjugation with GNPs and for subsequent animal immunization. The GNP diameter was measured by TEM, the average particle size was $15.7 \mathrm{~nm}$. Analysis of the antibody titer data showed that the titer produced by immunization with GNP-antigen conjugates $(1: 15018.67 ; p=$ 0.0014 ) was higher than that produced by immunization with unconjugated TGEV antigen (1:6826.67).

In immunology, the mononuclear phagocyte system (MPS) (also known previously as the reticuloendothelial or macrophage system) is part of the immune system that consists of phagocytic cells located in reticular connective tissue. The cells are primarily monocytes and macrophages, which accumulate in lymph nodes and in the spleen. The effectiveness of interaction of the GNP-antigen conjugate with cells of the reticuloendothelial system was evaluated using the MTT test. On day 10 after immunization, an increase in the respiratory activity of macrophages was noted (Fig. 4). After immunization with the GNP-antigen conjugate, the activity increased by $97 \%(p=0.003)$ as compared with the control and by $75 \%$ $(p=0.0015)$ as compared with the immunization with TGEV antigen and 79\% $(p=0.006)$ as compared with GNP.

A study of the respiratory activity of splenic lymphoid cells (Fig. 5) showed that after immunization with the conjugate, the activity increased 2.2-fold, as compared to the control, whereas after immunization with TGEV antigen alone, it did not change much.

The data demonstrate that immunization of animals with TGEV antigen-GNPs not only activates antigen-presenting cells but also increases the proliferative activity of splenic lymphoid (antibody-forming) cells. This indicates that GNPs can present antigens to the organs of the endothelial system. The effect of the conjugate on humoral immunity was assessed by comparing changes in the cytokine concentration between the control and experimental animals.

There was a statistically significant increase in the content of the $\gamma$-IFN in animals immunized with GNP-antigen conjugates (Fig. 6). These animals had the highest content of $\gamma$-IFN $\left(59.5 \pm 13.6 \mathrm{pgml}^{-1} ; p=0.023\right)$ this group was comparison with group which received only physiological saline (control group). We determined the $p$ value error probability when deviating from the null hypothesis (errors of the first kind). We determined that for our research, $p$ was $\leq 0.05$. When the animals were given the native antigen and GNPs, no appreciable changes in $\gamma$-IFN content were found.

The content of IL-1 $\beta$ in animals immunized with GNPantigen conjugate was $120.4 \pm 23.28 \mathrm{pgml}^{-1}(p=0.05)$, which is higher than it was in intact animals $\left(91.04 \pm 17.01 \mathrm{pgml}^{-1}\right)$ or in animals given the antigen alone $\left(91.46 \pm 17 \mathrm{pgml}^{-1} ; p=\right.$ $0.96)$ and GNPs $\left(107 \pm 20.6 \mathrm{pgml}^{-1} ; p=0.16\right)$ (Fig. 7) $(p$ 


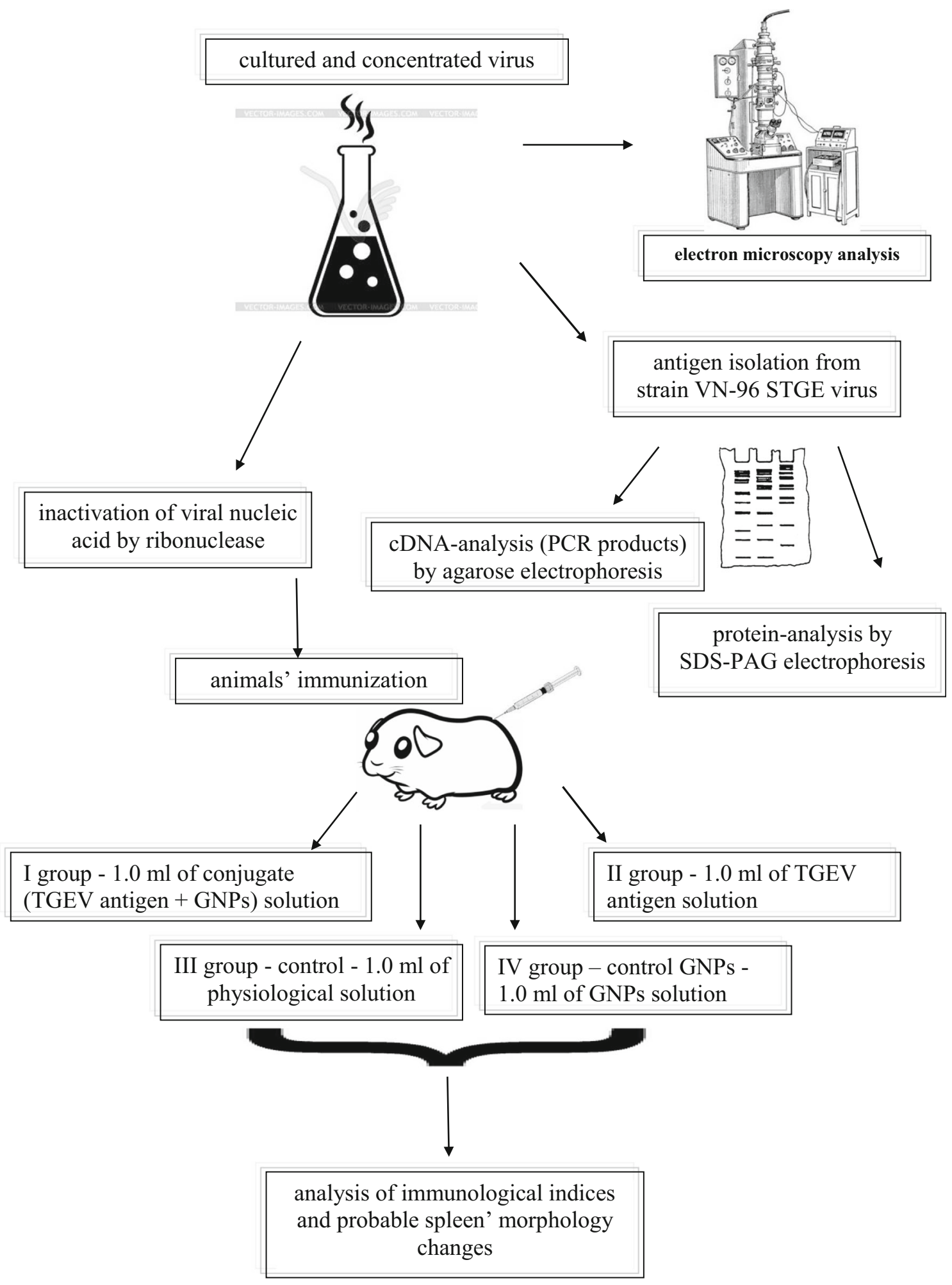

Fig. 1 General experimental scheme

value for GNP-antigen group was comparison with group which received only physiological saline (control group). GNP-antigen group was comparison with group which received only physiological saline (control group). The increased concentration of IL-1 $\beta$ in the immunized animals directly correlated with the activity of macrophages and stimulated B cells, which produce this cytokine when activated. This point is so important, since it is desirable to avoid an 
Fig. 2 Electrophoregram of structural proteins in a purified preparation of the TGEV strain VN-96 (A). Molecular size markers (B)

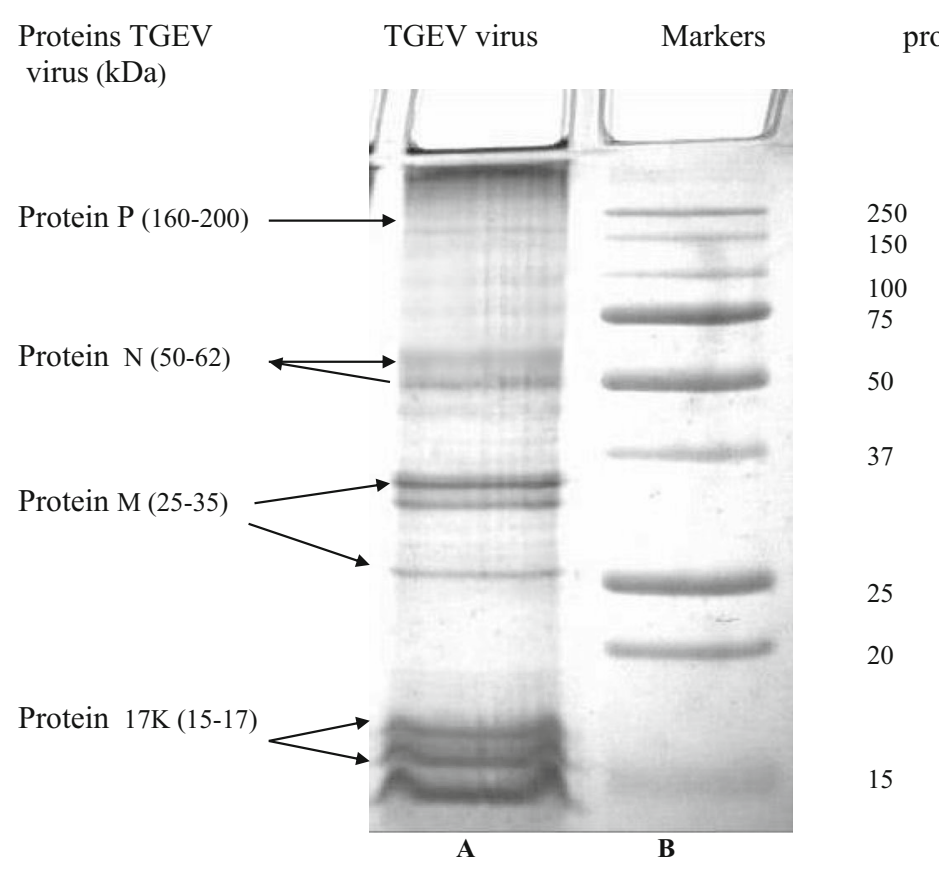

protein markers (kDa) inflammatory process during immunization, which results in the appearance of granulomas.

Similar data were obtained with IL-6 (Fig. 8). This fact indicates that the injected preparations are stimulatory to cellular immunity.

It is known that interferons, which possess protective properties, are produced in the body only when the virus enters or tumor diseases. That is why the analysis of the effect of immunization with the help of gold nanoparticles on the change in the level of interferon was made. It was found that in the immunized group, the concentration of interferon increased by $74 \%$ (compared to the control) against $29 \%$ for the group immunized with the antigen. When immunizing animals with native antigen, no significant changes in the concentration of interferon in blood serum of the immunized animals were observed. Thus, an increase in the concentration of interferon indicates the stimulation of the introduced drugs of the cell link of immunity.

The results obtained correlate with research in this area by other scientists. For example, in work (Zhang et al. 2018) showed that TGEV N protein induced ER stress and activated NF- $k B$, which was responsible for the upregulation of IL-8
Fig. 3 Electrophoregram of PCR products of cDNA from a purified preparation of the TGEV strain VN-96 (A). Negative control - (K) $(-)$; Molecular size markers:

"DNA Ladder 100 marker" (M)

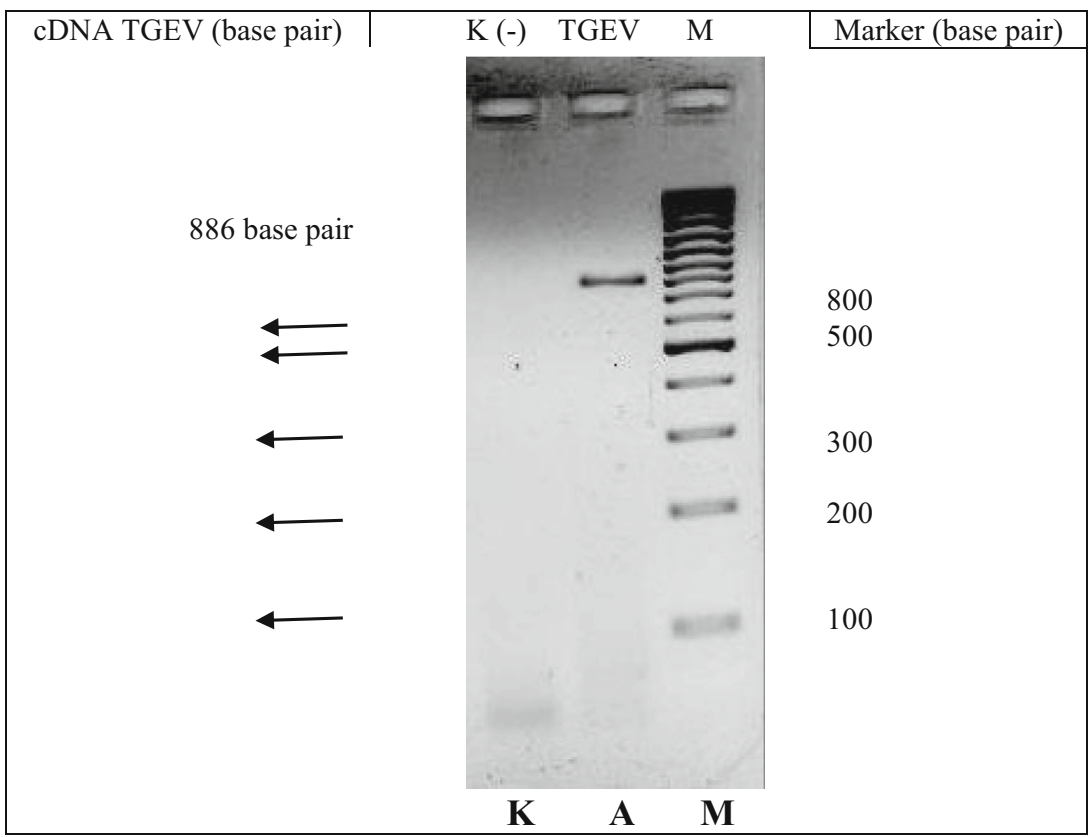


Fig. 4 Influence of TGEV antigen-GNPs on the animals' peritoneal cells (TGEV antigen $p=0.006$; GNP-antigen conjugate $p=0.003 ;$ GNPs $p=0.0015$ )

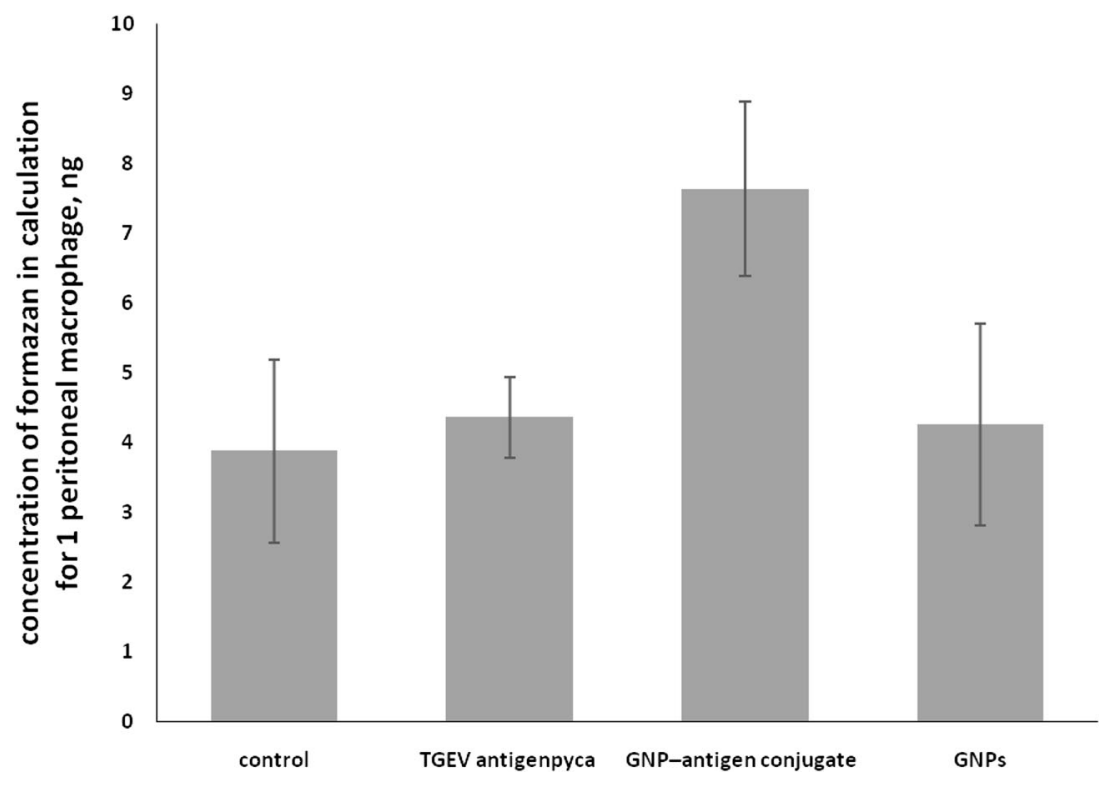

and Bcl-2 expression. Tao et al. (2017) also revealed an increase in the concentration of cytokines including interferon gamma and interleukin 1 in response to immunization AuNP$\mathrm{M} 2 \mathrm{e}+\mathrm{sCpG}$. But he mainly considered the reaction of splenocytes to a given complex (their reaction, which was expressed in the production of cytokines, on the effect of AuNP) was studied. In addition, AuNP-M2e was administered together with $\mathrm{sCpG}$ which is a strong immunomodulator. It was interesting for us to look at the production of these cytokines in the body as a whole and to reveal the general clinical changes that can develop on the introduction of antigen and AuNP.

One can speculate that GNPs facilitate antigen expression with the major histocompability complex on the surface of antigen-presenting cells. This subsequence ensures that the viral peptides are effectively presented to cytotoxic $\mathrm{T}$ lymphocytes and natural killers. Our data for the increase in $\gamma$-IFN activity are in agreement with those for the increase in the respiratory activity of splenocytes on day 10 after the last injection, another indication that colloidal gold can stimulate the release of $\gamma$-IFN by T cells, thereby enhancing the activity of lymphoid immunity.

In guinea pigs, the spleen forms leucocytes and removes old red blood cells (erythrocytes). The spleen framework is formed by trabeculae, which consist of reticular connective tissue, smooth muscle cells, and blood vessels (at the same time, the spleen contains only efferent lymphatic vessels). The reticular connective tissue includes both red and white pulp. The white pulp is a lymphoid tissue that produces immune and blood cells. The red pulp functions to filter blood for antigens, microorganisms, and defective red blood cells; therefore, it contains various blood corpuscles, including large and small
Fig. 5 Influence of TGEV antigen-GNPs on the animals' spleen lymphoid cells (TGEV antigen $p=0.69$; GNP-antigen conjugate $p=0.016$; GNPs $p=$ 0.18 )

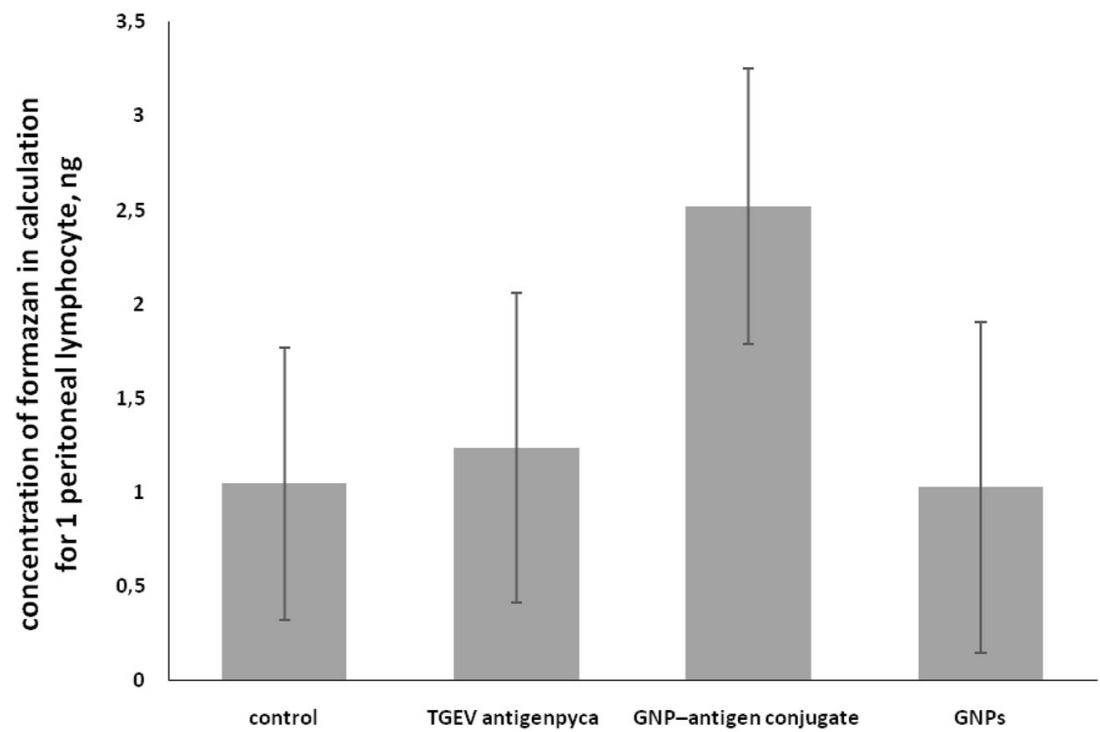


Fig. 6 Increase in the content of $\gamma$-IFN in animals immunized with GNP-antigen conjugates (TGEV antigen $p=0.2$; GNP-antigen conjugate $p=0.023$; GNPs $p=$ 0.087)

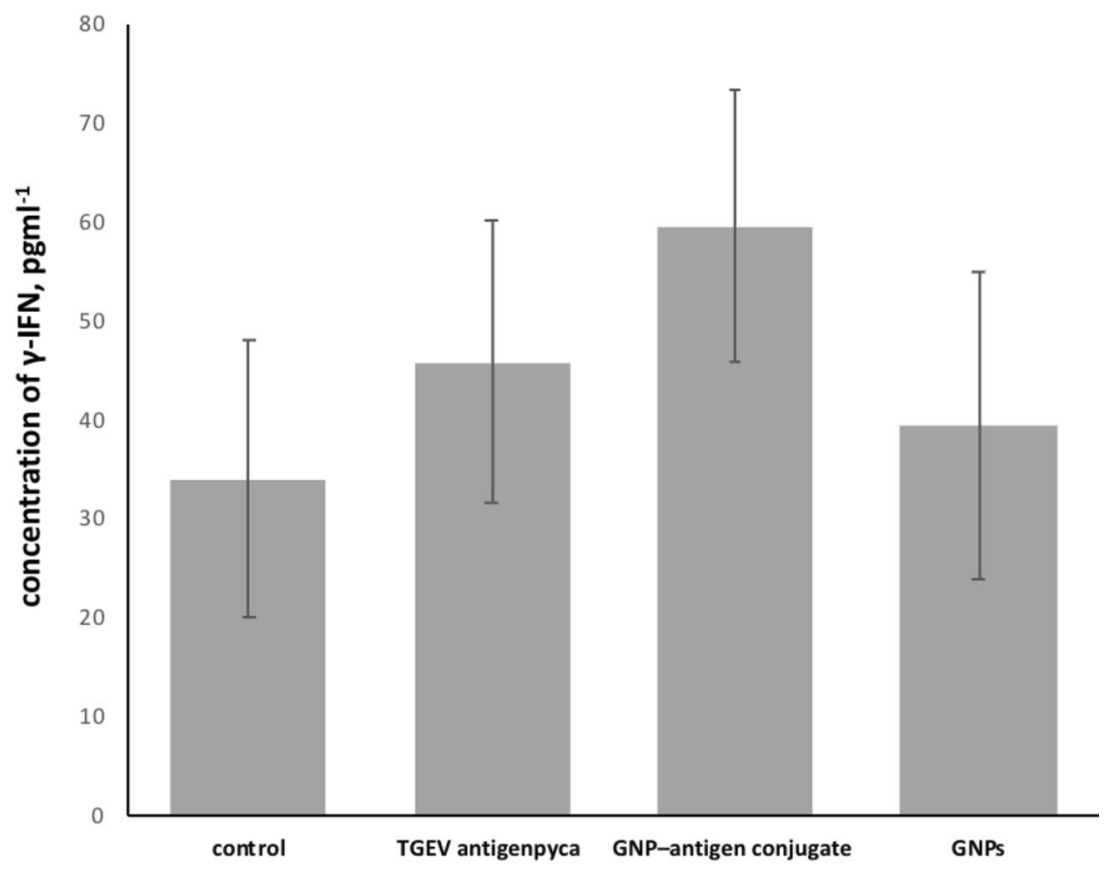

lymphocytes, immature leucocytes, leucocytes at the final stage of graininess, and disintegrating erythrocytes. The spleen is also important for the development of humoral immunity and is a B-system organ.

In the animals immunized with GNP-antigen conjugates, the lymphoid follicles had distinct boundaries and contained large number of densely spaced lymphoid cells (Fig. 9c. The lymphoid tissue was well structured and was located in a compact manner. There was a clear boundary between the red and white pulp regions, and there were full of cellular elements.

For comparison, we analyzed morphological changes in the spleens of the animals immunized with TGEV antigen alone. The observed changes were characterized by the existence of perivascular edema (Fig. 9d), sometimes accompanied by proliferation and desquamation of the vessels' endothelium. Moreover, the lymphoid tissue of the follicles became sparse, and the number and density of lymphoid cells decreased. In spleen tissue sections from the animals immunized with TGEV antigen alone, the boundary between red and white pulp was less clear, the size and total number of follicles in the microscopic field decreased, and no germinative centers could be detected. These results point to degradative processes in the immune organs of the animals.

In the control group of guinea pigs and GNPs, injected with physiological saline, no morphological changes in spleen tissue were observed (Fig. 9a, b).
Fig. 7 Concentration of IL- $1 \beta$ in animals immunized with GNPantigen conjugates (TGEV antigen $p=0.96$; GNP-antigen conjugate $p=0.05$; GNPs $p=0.16$ )

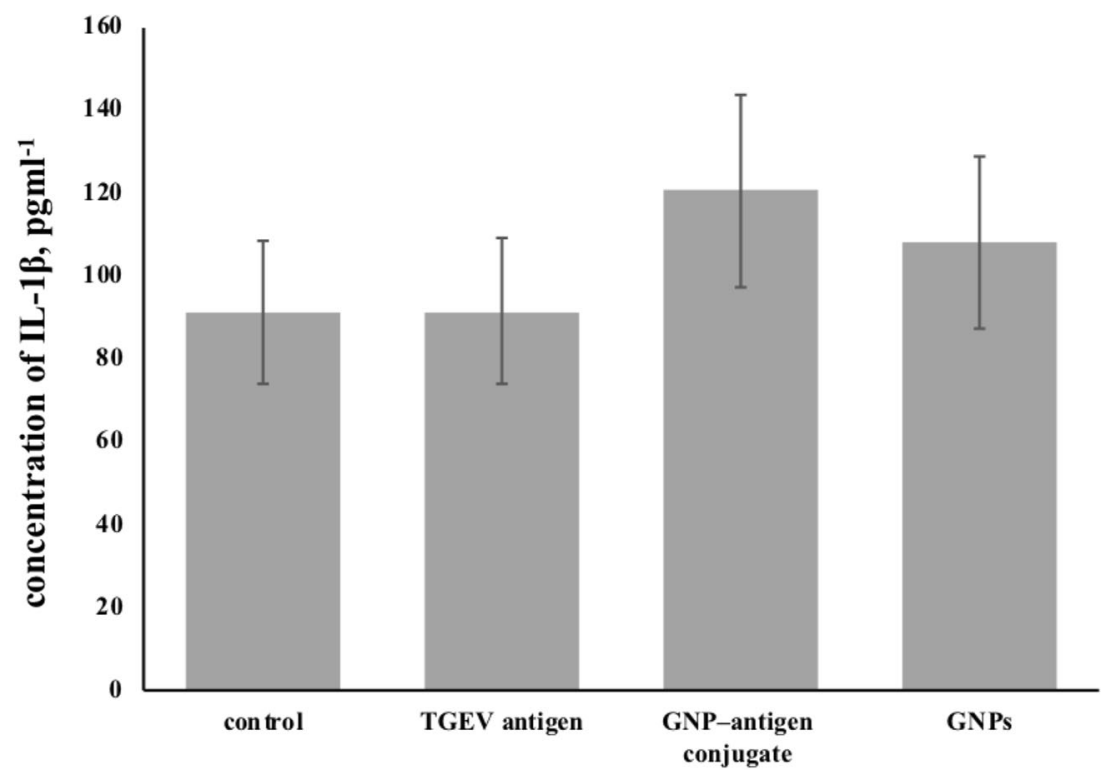


Fig. 8 Concentration of IL-6 in animals immunized with GNPantigen conjugates (TGEV antigen $p=0.95$; GNP-antigen conjugate $p=0.002$; GNPs $p=0.08$ )

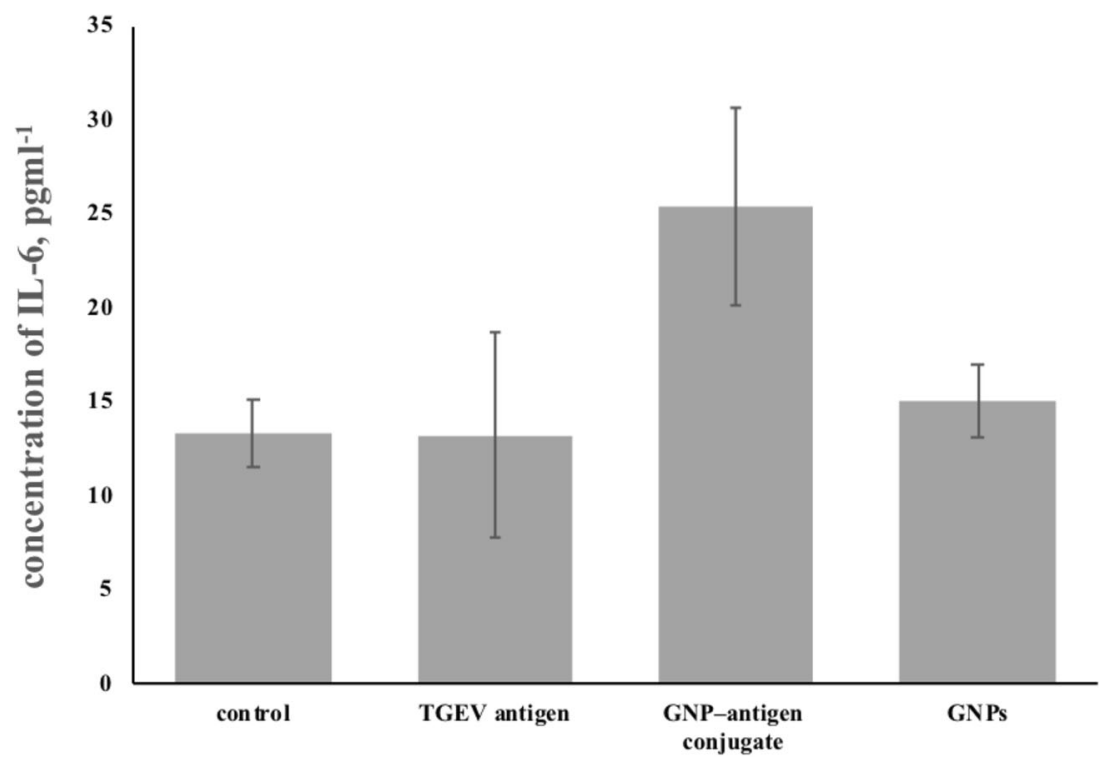

\section{Discussion}

Gold nanoparticles are stable metallic nanoparticles which have excellent surface functional chemistry, high biocompatibility, and nil toxicity (Pissuwan et al. (2008). In addition, gold nanoparticles can be easily synthesized, giving them shapes such as spheres, rods, cubes, stars, and pyramids. This quality allows the use of gold nanoparticles for a variety of purposes, including vaccine delivery (Versiani et al. 2016).
There are a series of works devoted to the use of gold nanoparticles as carriers of antigens for pathogens such as the virus grippe (Tao et al. 2014), virus foot-and-mouth (Chen et al. 2010), tetanus toxoid (Barhate et al. 2013), and Yersinia pestis (Gregory et al. 2012).

In our work, we used spherical gold nanoparticles (average diameter, $15 \mathrm{~nm}$ ) as a platform for the antigen for TGEV. The data demonstrate that immunization of animals with TGEV antigen-GNPs not only activates antigen-presenting cells but also increases the proliferative activity of splenic lymphoid
Fig. 9 a Spleen tissue section from the animals immunized GNPs. Hematoxylin-eosin staining; magnification, $\times 50$. b Spleen tissue section from the animals control group. Hematoxylineosin staining; magnification, $x$ 50. c Spleen tissue section from the animals immunized with TGEV antigen-GNPs.

Hematoxylin-eosin staining; magnification, $\times 50$. Lymphoid follicles have distinct boundaries. d Spleen tissue section from the animals immunized with TGEV antigen alone. Hematoxylineosin staining; magnification, $x$ 50. Perivascular edema and sparse lymphoid tissue in the follicles can be observed
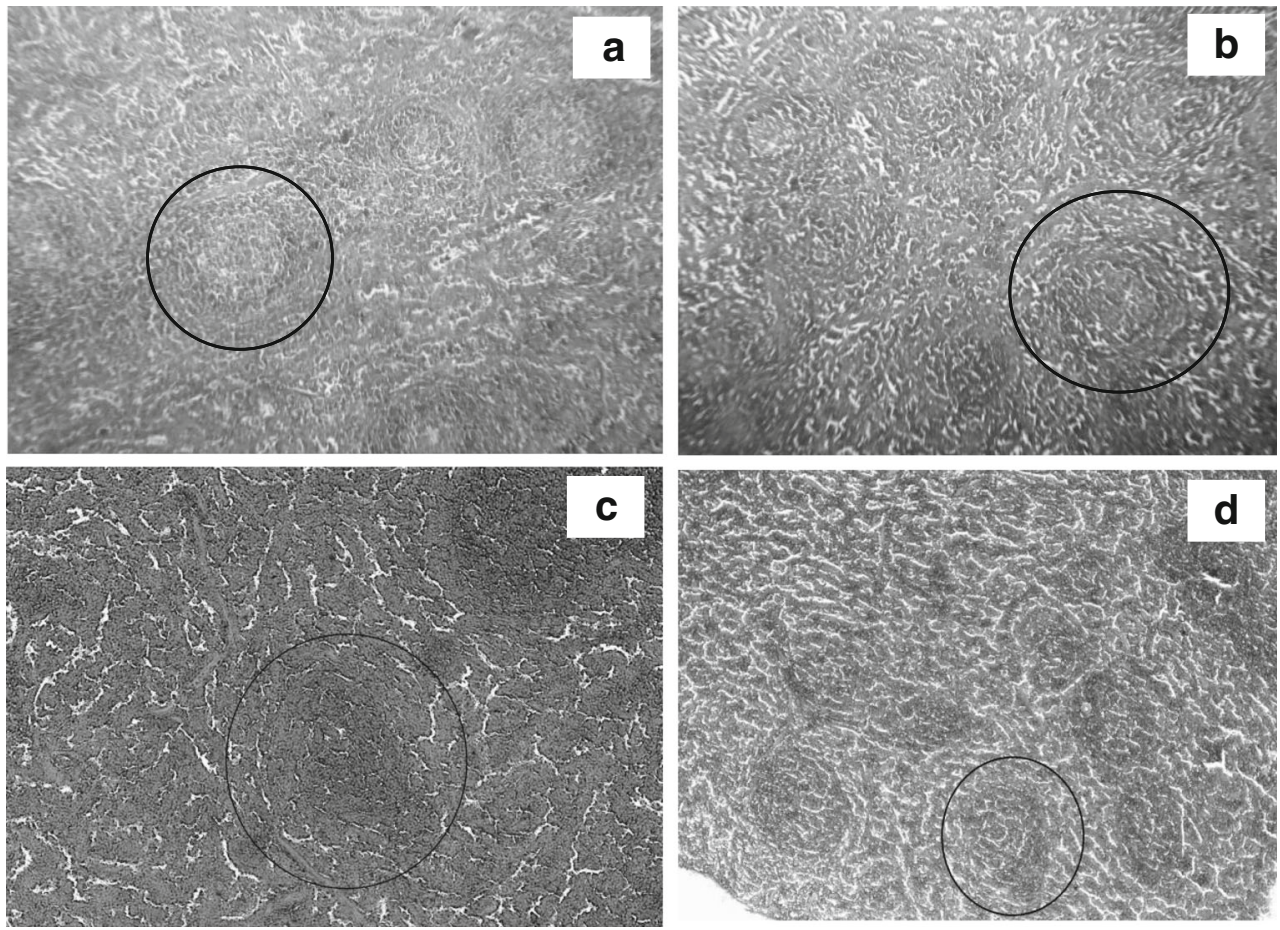
(antibody-forming) cells. The contents of $\gamma$-IFN, IL- $1 \beta$, and IL-6 in animals immunized with GNP-antigen conjugates were higher than those in the intact animals or in animals given the antigen alone. The increased concentration of IL$1 \beta$ in the immunized animals directly correlated with the activity of macrophages and stimulated B cells, which produce this cytokine when activated. The increased concentration of IL-6 indicates that the injected preparations are stimulatory to cellular immunity.

Several reports have described the development and use of nanostructures for stimulating cellular immunity. For example, Xu et al. (2012) showed that gold nanorods associated with the DNA vaccine may cause increased formation of $\gamma$-IFN in HIV-infected mice. Assis et al. (2018) showed that gold nanorods, functionalized with cysteamine and associated with the protein $\mathrm{rSm} 29$, are stimulatory to IL-1. In a work, Tao et al. (2017) showed that the use of nanostructured vaccine led to an increase in the concentration of IgG2a, IgA, and IL-1a, IL-2, IL-17, TNF- и RANTES. Our research correlates with these studies but in the present work we used gold nanoparticles for the first time as a platform for antigen for TGEV. Also, we did nonspecific adsorption of the antigen and did not perform a chemical surface functionalization. This made it possible to simplify the conjugation process, as well as to remove additional procedures related to the purification of the drug from toxic components. Additionally we analyzed the morphological changes in the spleens of the animals immunized with GNP-antigen conjugates and TGEV antigen.

The microanatomical changes (increased number of follicles) indicate the activation of the B-dependent zone of the spleen and, consequently, the development of a humoral-type immunological reaction (Galaktionov, 2000). The degradative processes observed in the animals immunized with TGEV antigen alone are evidence of weak resistance to pathogen attack.

In conclusion, immunization with TGEV antigen conjugated to GNPs as a carrier activates the respiratory activity of lymphoid cells and peritoneal macrophages, which is directly related to their transforming activity and to activation of antibody generation. Furthermore, the use of this conjugate allows marked improvement of the structure of the animals' immune organs and restores the morphological-functional state of these organs. The results of this study can be used in the further development of nanovaccines against swine transmissible gastroenteritis. The microanatomical changes (increased number of follicles) indicate the activation of the B-dependent zone of the spleen and, consequently, the development of a humoral-type immunological reaction (Galaktionov, 2000). The degradative processes observed in the animals immunized with TGEV antigen alone are evidence of weak resistance to pathogen attack.
Funding information This study was funded by the Russian Science Foundation (project no. 18-14-00016).

\section{Compliance with ethical standards}

Conflict of interest The authors declare that they have no conflict of interest.

Ethical statement All applicable international, national, and/or institutional guidelines for the care and use of animals were followed.

\section{References}

Assis NRG, Caires AJ, Figueiredo BC, Morais SB, Mambelli FS, Marinho FV, Ladeira LO, Oliveira SC (2018) The use of gold nanorods as a new vaccine platform against schistosomiasis. J Control Release 275:40-52

Barhate G, Gautam M, Gairola S, Jadhav S, Pokharkar V (2013) Quillajasaponaria extract as mucosal adjuvant with chitosan functionalized gold nanoparticles for mucosal vaccine delivery: stability and immunoefficiency studies. Int J Pharm 441(1):636-642

Bernas T., Dobrucki J.W. (2000) The role of plasma membrane in bioreduction of two tetrazolium salts, MTT, and CTC, Arch Biochem Biophys 380: 108-116

Bhattacharya R, Mukherjee P (2008) Biological properties of "naked" metal nanoparticles. Adv Drug Del Rev 60:1289-1306

Chen YS, Hung YC, Lin WH, Huang GS (2010) Assessment of gold nanoparticles as a size-dependent vaccine carrier for enhancing the antibody response against synthetic foot-and-mouth disease virus peptide. Nanotechnology 21(19):195101

Cheng QH, Niu XY (1992) Investigation on the porcine epidemic diarrhea prevalent on Qinhai. Vet Sci 22:22-23

Delmas B, Gelfi J, Laude H (1986) Antigenic structure of transmissible gastroenteritis virus. II. Domains in the peplomer glycoprotein. J Gen Virol 67:1405-1418

Dreaden EC, Alkilany AM, Huang X, Murphy CJ, El-Sayed MA (2012) The golden age: gold nanoparticles for biomedicine. Chem Soc Rev 41:2740-2779

Dykman LA, Khlebtsov NG (2012) Gold nanoparticles in biomedical applications: recent advances and perspectives. Chem Soc Rev 41: 2256-2282

Dykman LA, Staroverov SA, Bogatyrev VA, Shchyogolev SY (2010a) Adjuvant properties of gold nanoparticles. Nanotechnol 5(11-12): 748-761 (in Russian)

Dykman LA, Staroverov SA, Bogatyrev VA, Shchyogolev SYu (2010b) Gold nanoparticles as an antigen carrier and an adjuvant. Nova science publishers, New York p 54

Dykman LA, Bogatyrev VA, Shchyogolev SYu, Khlebtsov NG (2008) Gold nanoparticles: synthesis, properties, biomedical applications. Nauka, Moscow (in Russian)

Fedorova AA, Azzami K, Ryabchikova EI, Spitsyna YE, Silnikov VN, Ritter W, Gross HJ, Tautz J, Vlassov VV, Beier H, Zenkova MA (2011) Inactivation of a non-enveloped RNA virus by artificial ribonucleases: honey bees. Antivir Res 91:267-277

Frens G (1973) Controlled nucleation for the regulation of the particle size in monodisperse gold suspensions. Nature Phys Sci 241:20-22

Gregory AE, Williamson ED, Prior JL (2012) Conjugation of Y. pestis F1-antigen to gold nanoparticles improves immunogenicity. Vaccine 30(48):6777-6782

Herrington CS, McGee J O'D (eds) (1993) Diagnostic Molecular Pathology: A Practical Approach. Oxford University Press, Oxford 
Horzinek MC, Lutz H, Pedersen NC (1982) Antigenic relationships among homologous structural polypeptides of porcine, feline, and canine coronaviruses. Infect Immun 37(3):1148-1155

Khlebtsov NG, Dykman LA (2010) Optical properties and biomedical applications of plasmonic nanoparticles. J Quant Spectrosc Radiat Transf 111:1-35

Leiter EH (2001) In: Coligan JE, Kruisbeek AM, Marguilies DH, Shevach EM, Strober W (eds) The NOD mouse: a model for insulin dependent diabetes mellitus //Current protocols in immunology. vol 3. John Wiley \& Sons, New York, pp 15.9.1-15.9.23

Maniatis T, Fritsch EF, Sambrook J (1982) Molecular cloning: a laboratory manual. Cold Spring Harbor Laboratory, New York

Martins AMCRPF, Bersano JG, Ogata R, Amante G, Nastari BDB, Catroxo MHB (2013) Diagnosis to detect porcine transmissible gastroenteritis virus (TGEV) by optical and transmission electron microscopy techniques. Int J Morphol 31:706-715

Mout R, Moyano DF, Rana S, Rotello VM (2012) Surface functionalization of nanoparticles for nanomedicine. Chem Soc Rev 41:2539-2544

Moxley RA, Olson LD (1989) Clinical evaluation of transmissible gastroenteritis virus vaccines and vaccination procedures for inducing lactogenic immunity in sows. Am J Vet Res 50:111-118

Patent RU2009124039A (2009)

Pissuwan D, Valenzuela SM, Cortie MB (2008) Prospects for gold nanorodparticles in diagnostic and therapeutic applications. Biotechnol Genet Eng Rev 25(1):93-112

Staroverov SA, Fomin AS, Volkov AA, Koslov SV, Khlebtsov BN, Larionov SV, Vasilenko OA, Megennei PV, Vinnikov NT, Dykman LA (2012) Usage of phage mini-antibodies as means of detecting ferritin concentration in animal blood. Russian Veterinary Journal Productive animals 4:30-33 (in Russian)

Straw BE, D'Allaire S, Mengeling WL, Taylor DJ (eds) (2000) Disease of swine. Iowa State University Press, Ames

Sturman LS, Riehard CS, Holmes KV (1985) Proteolytic cleavage of the E2 glyco protein of murine coronavirus by trypsin and separation of two different 90K cleavage fragments. J. Gen. Virol. 56:904-911

Tao W, Ziemer KS, Gill HS (2014) Gold nanoparticle-M2e conjugate coformulated with $\mathrm{CpG}$ induces protective immunity against influenza A virus. Nanomedicine (Lond) 9(2):237-251

Tao W, Hurst BL, Shakya AK, Uddin MJ, Ingrole RS, HernandezSanabria M, Arya RP, Bimler L, Paust S, Tarbet EB, Gill HS (2017) Consensus M2e peptide conjugated to gold nanoparticles confers protection against $\mathrm{H} 1 \mathrm{~N} 1, \mathrm{H} 3 \mathrm{~N} 2$ and $\mathrm{H} 5 \mathrm{~N} 1$ influenza $\mathrm{A}$ viruses. Antivir Res 141:62-72. https://doi.org/10.1016/j.antiviral. 2017.01.021

Versiani AF, Andrade LM, Martins EMN (2016) Gold nanoparticles and their applications in biomedicine. FutureVirol 11(4):293-309

Wesley RD, Woods RD, Cheung AK (1991) Genetic analysis of porcine respiratory Coronavirus, an attenuated variant of transmissible gastroenteritis virus, J. Virol 65:3369-3373

Xu L, Liu Y, Chen Z, Li W, Wang L, Wu X, Ji Y, Zhao Y, Ma L, Shao Y, Chen C (2012) Surface-engineered gold nanorods: promising DNA vaccine adjuvant for HIV-1 treatment. Nano Lett 12:2003-2012

Zhang Q, Xu Y, Chang R, Tong D, Xu X (2018) Transmissible gastroenteritis virus $\mathrm{N}$ protein causes endoplasmic reticulum stress, upregulates interleukin- 8 expression and its subcellular localization in the porcine intestinal epithelial cell. Res Vet Sci 119:109-115. https://doi.org/10.1016/j.rvsc.2018.06.008 